\title{
Gomphrena globosa L. as a novel source of food-grade betacyanins: Incorporation in ice-cream and comparison with beet-root extracts and commercial betalains
}

\author{
Custódio Lobo Roriz ${ }^{\mathrm{a}, \mathrm{b}}$, João C.M. Barreira ${ }^{\mathrm{a}}$, Patricia Morales ${ }^{\mathrm{b}}$, Lillian Barros ${ }^{\mathrm{a}}$, \\ Isabel C.F.R. Ferreira ${ }^{\mathrm{a}, *}$ \\ ${ }^{a}$ Centro de Investigação de Montanha (CIMO), Instituto Politécnico de Bragança, Campus de Santa Apolónia, 5300-253 Bragança, Portugal \\ b Dpto. Nutrición y Bromatología II, Facultad de Farmacia, Universidad Complutense de Madrid (UCM), Plaza Ramón y Cajal, s/n. E-28040, Madrid, Spain
}

\section{A R T I C L E I N F O}

\section{Keywords:}

Natural colourants

Ice-cream

Nutritional composition

Colour parameters

Fatty acids

\begin{abstract}
A B S T R A C T
Currently, there are some examples of natural colourants with commercial use. However, these colourants are usually under-exploited, besides being obtained from a reduced number of plant or algal species. Accordingly, we propose using betalains obtained from an alternative plant species, Gomphrena globosa, which have a powerful colouring activity besides being strong antioxidants, as a novel ice-cream colourant. For comparison purposes, other ice-cream formulations were prepared, namely without colourants, added with commercial betalain or with Beta vulgaris extract. Besides evaluating the colour parameters $L^{*}, a^{*}$ and $b^{*}$, the nutritional parameters, individual sugars and fatty acids profiles were also studied. These parameters were evaluated throughout time, up to a maximum of 60 days of freeze $\left(-22^{\circ} \mathrm{C}\right)$ storage. Betacyanin quantification of each formulation was also performed to determine its maintenance along storage. In general, ice-creams prepared with G. globosa were similar (considering nutritional, colour, individual sugars and fatty acids profiles) to those including B. vulgaris extract, thereby validating the suitability of this alternative plant as a source of food colourants, particularly as ice-cream colourants. Furthermore, the positive effects induced by the addition of this natural colourant were maintained throughout storage time, as indicated by the markers distribution in the linear discriminant analysis.
\end{abstract}

\section{Introduction}

The importance of food appearance might be considered as being as important as its taste, being often considered as a top indicator of the overall quality of food (Bridle \& Timberlake, 1997, pp. 103-109). Nowadays, the complex processing that most food products are submitted to might cause some unwanted changes to their visual appearance, especially by causing a fading effect in their colour (González, Gallego, \& Valcárcel, 2002). In addition, there is growing concern about the health effects potentially induced by food, which is increasingly being considered as having the double purpose of satisfying nutritional needs, while exerting disease-preventing effects. This overall trend represents the main foundation of the functional foods market, in which novel food products, able to provide new consuming experiences, are continuously being developed (Edmonds, Wadhwa, \& Wibisono, 2013). When these products are developed with the main purpose of achieving specific functional properties, foods poor in bioactive compounds present higher necessity of improvement. In this sense, ice-cream, a product with high consumption level, would certainly benefit from the incorporation of bioactive natural substances, particularly if these substances could simultaneously improve its appearance (Edmonds et al., 2013). In general, frozen dairy desserts, such as ice-creams, are complex colloidal systems that consist in a combination of milk, sweeteners, emulsifiers, stabilizers, colouring and flavouring agents (Soukoulis, Lyroni, \& Tzia, 2010). Despite the generalized use of artificial substances, most of these agents could be obtained from natural sources, making the resulting products very appealing to the consumers (Erkaya, Dağdemir, \& Sengül, 2012).

In the case of colouring agents, and owing to the important role of colour when enjoying any food product or as a potential indicator of food quality (Bridle \& Timberlake, 1997, pp. 103-109), it is mandatory to find natural-based colourants, particularly if the associated compounds might exert any kind of bioactivity. This becomes even more important if we remind that most artificial compounds are often regarded as causing several secondary and harmful effects, such as allergenic or intolerance reactions (Wissgott \& Bortlik, 1996).

\footnotetext{
* Corresponding author.

E-mail address: iferreira@ipb.pt (I.C.F.R. Ferreira).
} 
Despite the diversity of natural dyes (e.g., carotenoids, anthocyanins or betalains) in the market (Carocho, Morales, \& Ferreira, 2015), most are far from being used according to their full potential, besides being obtained from a reduced number of natural sources. Betalains, which can be divided in red-violet betacyanins and yellow-orange betaxanthins, are a good example of under-exploited natural food colourants. Furthermore, betacyanins are almost exclusively obtained from beetroot, despite the availability of other alternative sources (Roriz, Barros, Prieto, Morales, \& Ferreira, 2017). Besides their colouring capacity, these pigments have a high antioxidant activity, exerting also different chemopreventive effects (Spórna-kucab \& Jagodzi, 2017). Gomphrena globosa L. presents a multitude of phytochemicals with interest, such as tocopherols, sugars and organic acids (Roriz, Barros, Carvalho, \& Ferreira, 2014). In addition to these compounds, other substances with antioxidant properties have been identified in this plant, in particular bioactive substances such as phenolic compounds, but also molecules that can confer colour, such as betacyanins (Roriz, Barros, Carvalho, Santos-Buelga, \& Ferreira, 2014). Herein, betacyanins extracted from the purple flowers of Gomphrena globosa L. (Amaranthaceae) were evaluated as colouring/functionalizing agents in ice-cream formulations, aiming to verify its potential improvement in colour parameters, as well as its effect on nutritional composition, individual sugars and fatty acids profiles. In order to acquire comprehensive conclusions, other ice-cream formulations were prepared namely, ice-cream without any colouring agent, ice-cream incorporated with commercial betalains and ice-cream added with beet-root extract. Betacyanin quantification of each formulation was also performed in order to determine its maintenance along storage. All parameters were analysed in five different moments: preparation day, and after 15, 30, 45 and 60 days (considered as the maximum desired storage limit, for this type of icecream) of storage $\left(-22^{\circ} \mathrm{C}\right)$.

\section{Material and methods}

\subsection{Standard and reagents}

Acetonitrile (HPLC grade) was obtained from Lab-Scan (Lisbon, Portugal). The standard betalain and the fatty acids methyl ester (FAME) reference standard mixture 37 (standard 47885-U) was purchased from Sigma-Aldrich (St. Louis, MO, USA). Other reagents and solvents (analytical grade) were obtained from common sources. Milk (UHT entire milk Continente, composition per $100 \mathrm{~mL}: 273 \mathrm{KJ}$, or $65 \mathrm{Kcal}$ energetic value; $3.6 \mathrm{~g}$ of lipids of which 2.3 are unsaturated; $4.9 \mathrm{~g}$ of carbohydrates, being the majority sugars; $3.3 \mathrm{~g}$ of protein; and $0.1 \mathrm{~g}$ of salt) and double cream (UHT cream Continente; composition per $100 \mathrm{~mL}: 1385 \mathrm{KJ}$, or $336 \mathrm{Kcal}$ energetic value; $35 \mathrm{~g}$ of lipids of which $20 \mathrm{~g}$ are unsaturated; $3 \mathrm{~g}$ of carbohydrates; $2 \mathrm{~g}$ of protein; and $0.1 \mathrm{~g}$ of salt) were purchased at a local supermarket (Continente, Portugal). Water was treated in a Milli-Q water purification system (TGI Pure Water Systems, Greenville, SC, USA).

\subsection{Sample collection}

Gomphrena globosa L. samples were obtained from Ervital, a company established in a mountain region with high biodiversity, holding a vast collection of certified plant materials from different origins, obtained from sustainable harvesting of spontaneous local species and organic farming of exogenous ones. The botanical identification of the samples was confirmed by a botanical expert, responsible for the medicinal plant collection of Escola Superior Agrária herbarium (BRESA), Polytechnic Institute of Bragança (Trás-os-Montes, Portugal). After identification, samples were subjected to a mechanical treatment to separate the pigmented floral parts (bracts and bracteoles) from the inflorescences.

\subsection{Sample preparation}

\subsubsection{Ultrasound assisted extraction (UAE)}

The G. globosa extract enriched in betacyanins was obtained by UAE (QSonica sonicators, model CL-334, Newtown, CT, USA), working at $500 \mathrm{~W}$, for $22 \mathrm{~min}$, using water as the extraction solvent and a liquid-tosolid ratio of $5 \mathrm{~g} / \mathrm{L}$, as described by (Roriz, Barros, Prieto, Barreiro, et al., 2017).

\subsubsection{Preparation of B. vulgaris extract}

B. vulgaris extract obtained by UAE, was further filtrated and frozen prior to its lyophilization (FreeZone 4.5, Labconco, Kansas City, MO, USA), in order to obtain a dry extract.

\subsection{Incorporation of the natural food colorant in the ice-cream}

\subsection{1. a) Ice-cream preparation}

Ice-cream was prepared from a base recipe: $240 \mathrm{~g}$ of sugar were mixed with $500 \mathrm{~mL}$ of milk (UHT entire milk, Continente, Portugal), in order to dissolve the sugar. Meanwhile, $1000 \mathrm{~mL}$ of double cream (UHT cream, Continente, Portugal) were used to obtain whipped cream, which was previously added to the mixture. The final batter was left to stand for $12 \mathrm{~h}$, further divided in four batches, each placed in an icecream machine equipment (Ice-cream Maker SECN 12 A1, SilverCrest, Hamburg, Germany).

\subsection{2. b) Colouring agent addition}

The ice-cream batches were identified as: i) control (ice-cream without colouring agents); ii) ice-cream added with betalain standard ( $200 \mathrm{mg}$, i.e. $\approx 46 \mathrm{mg} / 100 \mathrm{~g}$ ice-cream); iii) ice-cream with $\mathrm{G}$. globosa extract $(670 \mathrm{mg}$, i.e. $\approx 154 \mathrm{mg} / 100 \mathrm{~g}$ ice-cream); iv) ice-cream with Beta vulgaris extract $(670 \mathrm{mg}$, i.e. $\approx 154 \mathrm{mg} / 100 \mathrm{~g}$ ice-cream).

The amount of each ingredient was added in order to obtain the desired colour. Moreover, the added quantities were different because commercial betalain (Sigma-Aldrich, St. Louis, MO, USA) is an isolated compound, obviously with a higher degree of purity in comparison with the extracts from $G$. globosa and B. vulgaris. B. vulgaris extract was obtained by grinding the sample with $10 \%$ of water, followed by a filtration step and freeze prior to its lyophilization (FreeZone 4.5, Labconco, Kansas City, MO, USA).

The samples were analysed immediately after preparation and after: 15, 30, 45 and 60 days (maximum desired storage limit for this type of ice-cream) of storage at $-22^{\circ} \mathrm{C}$.

\subsection{Nutritional composition and physico-chemical analyses}

\subsubsection{Nutritional parameters}

The samples were also analysed for proximate composition (moisture, protein, fat, ash and carbohydrates) using the AOAC procedures (AOAC, 2016). Crude protein content $(\mathrm{N} \times 6.38)$ was estimated by the Kjeldahl method (AOAC 978.04, AOAC, 2016); crude fat was determined by Rose-Gottlieb method (AOAC 905.02, AOAC, 2016); ash content was determined by incineration at $600 \pm 15^{\circ} \mathrm{C}$ (AOAC 923.03, AOAC, 2016); total carbohydrates were calculated by difference, taking into account moisture content, and the results were expressed in fresh weight. Total energy was calculated according to the following equation: Energy $(\mathrm{kcal})=4 \times(\mathrm{g}$ proteins $+\mathrm{g}$ carbohydrates $)+9 \times(\mathrm{g}$ lipids).

\subsubsection{Individual sugars}

Free sugars were detected by high performance liquid chromatography (HPLC) coupled to a refractive index detector. Sugars were identified by comparison with standards and further quantified $(\mathrm{g} /$ $100 \mathrm{~g}$ of ice-cream) by the internal standard (melezitose) method (Barros et al., 2013). 


\subsubsection{Colour parameters}

The CIE colour parameters were measured in three different points for each sample using a colorimeter (model CR-400, Konica Minolta Sensing Inc., Tokyo, Japan), and the average value of the different points was considered to determine this parameter. The illuminant $\mathrm{C}$ and a diaphragm aperture of $8 \mathrm{~mm}$ were selected. The Hunter colour $\mathrm{L}^{*}$, $a^{*}$ and $b^{*}$ values were registered using the data software "Spectra Magic Nx" (version CM-S100W 2.03.0006, Konica Minolta Company, Japan). The instrument was calibrated to standard white tiles before analysis (Spectra Magic NX Instruction Manual, Konica Minolta Sensing, Inc. (ver. 2.0), 2009, Japan) (Fernandes et al., 2012).

\subsubsection{Fatty acids}

Fatty acids were analysed by gas chromatography (GC) coupled to a flame ionization detector (FID) at $260^{\circ} \mathrm{C}$, using a DANI model GC 1000 instrument equipped with a split/splitless injector and a MachereyNagel (Duren, Germany) column (50\% cyanopropyl-methyl-50\% phenylmethylpolysiloxane, $30 \mathrm{~m} \times 0.32 \mathrm{~mm}$ i.d. $\times 0.25 \mu \mathrm{m} \mathrm{df}$ ). The oven temperature programme was as follows: the initial temperature of the column was $50^{\circ} \mathrm{C}$, held for $2 \mathrm{~min}$, then a $30^{\circ} \mathrm{C} / \mathrm{min}$ ramp to $125^{\circ} \mathrm{C}$, $5{ }^{\circ} \mathrm{C} / \mathrm{min}$ ramp to $160^{\circ} \mathrm{C}, 20^{\circ} \mathrm{C} / \mathrm{min}$ ramp to $180^{\circ} \mathrm{C}, 3^{\circ} \mathrm{C} / \mathrm{min}$ ramp to $200^{\circ} \mathrm{C}, 20^{\circ} \mathrm{C} / \mathrm{min}$ ramp to $220^{\circ} \mathrm{C}$ and held for $15 \mathrm{~min}$. The carrier gas (hydrogen) flow-rate was $4.0 \mathrm{~mL} / \mathrm{min}(0.61 \mathrm{bar})$, measured at $50^{\circ} \mathrm{C}$. Split injection (1:40) was carried out at $250^{\circ} \mathrm{C}$. Fatty acid identification was made by comparing the relative retention times of FAME peaks from samples with standards. The results were recorded and processed using the CSW 1.7 Software (DataApex 1.7) and expressed in relative percentage of each fatty acid (Barros et al., 2013).

\subsubsection{Betacyanins}

For betacyanins' determination an HPLC-DAD-ESI/MS analyses was performed with a Dionex Ultimate 3000 UPLC instrument (Thermo Scientific, San Jose, CA, USA) coupled with a diode-array detector and a mass spectrometer, as previously described by (Roriz, Barros, Prieto, Morales, et al., 2017). The separation was carried out in a Waters Spherisorb S3 ODS-2 C18, $(3 \mu \mathrm{m}, 4.6 \mathrm{~mm} \times 150 \mathrm{~mm}$, Waters, Milford, MA, USA) column operating at $35{ }^{\circ} \mathrm{C}$ and the solvents used were: (A) $0.1 \%$ trifluoracetic acid (TFA) in water and (B) acetonitrile, using a gradient flow elution method. Betacyanins maximum absorbance is $530 \mathrm{~nm}$, therefore this was the preference wavelength used to record all chromatograms. For quantitative analysis, a calibration curve was obtained based on gomphrenin III and betalain.

\subsection{Evaluation of hepatotoxicity}

The different extracts, the commercial standard and the final icecream formulations (maximal tested concentration: $400 \mu \mathrm{g} / \mathrm{mL}$ ) were evaluated regarding their hepatotoxicity, following a methodology previously described (Abreu et al., 2011) and using porcine liver, which was acquired from certified abattoirs. A phase-contrast microscope was used to monitor the growth of the cell cultures. They were sub-cultured and plated in 96 well plates (density of $1.0 \times 10^{4}$ cells/well). Dulbecco's Modified Eagle Medium (DMEM) was used, with $10 \%$ of foetal bovine serum (FBS), $100 \mathrm{U} / \mathrm{mL}$ of penicillin and $100 \mu \mathrm{g} / \mathrm{mL}$ of streptomycin. Ellipticine was used as a positive control, and the results were expressed in $\mathrm{GI}_{50}$ values (growth inhibition values) in $\mu \mathrm{g} / \mathrm{mL}$ (sample concentration that inhibited $50 \%$ of the net cell growth).

\subsection{Statistical analysis}

All statistical tests were performed with IBM SPSS Statistics for Windows, version 22.0 (IBM Corp., Armonk, NY, USA) considering a $5 \%$ significance level. Data were expressed as mean \pm standard deviation (the number of significant numbers was maintained according to the standard deviation magnitude).

For each ice cream formulation, three different samples were used.
Each of these samples was further analysed in triplicate. A 2-way analysis of variance (ANOVA) with type III sums, using the general linear model (GLM) procedure was applied to compare all parameters among different ice-cream formulations (IF) or storage times (ST). Besides evaluating the effect of each factor, their interaction was also assessed. When no statistical significant interaction was found, the means were compared using Tukey's multiple comparison test, with a previous assessment of the equality of variances through a Levene's test. Otherwise, differences were analysed in the estimated marginal means plots obtained for all levels of each factor.

In addition, a linear discriminant analysis (LDA) was used to compare the effect of IF and ST over all parameters simultaneously. A stepwise technique was applied, based on the Wilks' $\Lambda$ test with the usual probabilities of $F$ (3.84 to enter and 2.71 to be removed) for variable selection. Only variables with a statistically significant classification performance $(p<0.050)$ were maintained by the statistical model. This statistical classification tool was performed to estimate the relationship between single categorical dependent variables (ice-cream formulations) and the quantitative independent variables (results obtained in laboratorial assays). A leaving-one-out cross validation procedure was carried out to assess the model performance.

\section{Results and discussion}

Owing to the high consumers' acceptability, there are several studies reporting tentative improvements in ice-cream recipes, either by substituting its main ingredients, especially sugars (Moriano \& Alamprese, 2017; Soukoulis \& Tzia, 2017), or by adding compounds with different biological activity, e.g., probiotics (Chaikham \& Rattanasena, 2017; dos Santos Cruxen et al., 2017) or antioxidants (Sanguigni, Manco, Sorge, Gnessi, \& Francomano, 2016). There is an increasing tendency towards using natural extracts in recent studies (Carocho, Barreiro, Morales, \& Ferreira, 2014; dos Santos Cruxen et al., 2017), for instance to replace the artificial dyes commonly utilized in ice-cream, as shown in a recent study reporting the presence of 18 artificial dyes in different ice-cream formulations (Machewad, Chatge, Chappalwar, Jadhav, \& Chappalwar, 2012; Martin, Oberson, Meschiari, \& Munari, 2016). The industrial use of natural extracts might represent an effective answer to the current consumers' concerns, who are gradually preferring food products prepared with natural additives instead of artificial compounds, often associated with unwanted effects.

Bearing this in mind, four different ice-cream formulations: i) control ice-cream (CI, ice-cream with no added colourants); ii) ice-cream added with betalain standard (BSI); iii) ice-cream with G. globosa extract (GGI); and iv) ice-cream with B. vulgaris extract (BVI), were characterized. In addition to the preparation day, this comparative study was extended to four storage periods, namely: $15,30,45$ and 60 days at $-22^{\circ} \mathrm{C}$.

As explained in the Materials and methods section, the effect of storage time (ST) was evaluated after a previous aggregation of results obtained for all formulations in a determined period; likewise, the effect of ice-cream formulation (IF) was evaluated after combining the results of all storage periods in each specific IF. This approach is expected to allow concluding which is best colouring agent, independently of ST, as well as the main changes along storage in differently formulated icecreams. This is, in our opinion, the most useful information pertaining potential industrial applications. Since ST effect could depend on the ice-cream formulation (IF), and vice-versa, the interaction among both factors was also studied, in addition to evaluating the significance of each individual factor. In all cases where a significant $(p<0.050)$ interaction was found, not allowing the statistical classification of results, differences induced by each factor (if significant) were described according to the estimated marginal means (EMM) plots.

The nutritional composition and energy values for different icecream formulations (IF) and storage times (ST) are presented in Table 1. In terms of nutritional composition (Table 1), the interaction among IF 
Table 1

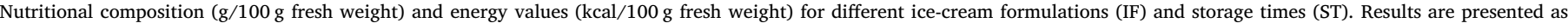
mean \pm standard deviation. ${ }^{1}$

\begin{tabular}{|c|c|c|c|c|c|c|c|c|c|}
\hline & & Water & Fat & Protein & Ash & Carbohydrates & Sucrose & Lactose & Energy \\
\hline \multirow[t]{5}{*}{ IF } & CI & $59 \pm 1$ & $14 \pm 2$ & $5.0 \pm 0.2$ & $0.35 \pm 0.05$ & $22 \pm 2$ & $19 \pm 1$ & $2.5 \pm 0.3$ & $234 \pm 13$ \\
\hline & BSI & $59 \pm 1$ & $15 \pm 1$ & $5.1 \pm 0.3$ & $0.35 \pm 0.05$ & $21 \pm 1$ & $18 \pm 1$ & $2.5 \pm 0.3$ & $239 \pm 6$ \\
\hline & GGI & $59 \pm 1$ & $15 \pm 1$ & $5.1 \pm 0.4$ & $0.37 \pm 0.05$ & $21 \pm 1$ & $18 \pm 1$ & $2.5 \pm 0.3$ & $239 \pm 7$ \\
\hline & BVI & $63 \pm 1$ & $13 \pm 1$ & $5.8 \pm 0.3$ & $0.37 \pm 0.05$ & $18 \pm 1$ & $16 \pm 1$ & $2.3 \pm 0.3$ & $212 \pm 7$ \\
\hline & ANOVA $p$-value $(n=45)^{2}$ & $<0.001$ & $<0.001$ & $<0.001$ & 0.243 & $<0.001$ & $<0.001$ & 0.036 & $<0.001$ \\
\hline \multirow[t]{6}{*}{ ST } & 0 days & $60 \pm 1$ & $14 \pm 1$ & $5.3 \pm 0.4$ & $0.43 \pm 0.05$ & $20 \pm 1$ & $17 \pm 1$ & $2.7 \pm 0.3$ & $227 \pm 8$ \\
\hline & 15 days & $60 \pm 1$ & $15 \pm 1$ & $5.3 \pm 0.5$ & $0.32 \pm 0.04$ & $20 \pm 2$ & $18 \pm 1$ & $2.3 \pm 0.2$ & $236 \pm 8$ \\
\hline & 30 days & $61 \pm 2$ & $12 \pm 2$ & $5.1 \pm 0.4$ & $0.42 \pm 0.05$ & $21 \pm 3$ & $18 \pm 1$ & $2.6 \pm 0.3$ & $212 \pm 11$ \\
\hline & 45 days & $60 \pm 2$ & $15 \pm 1$ & $5.3 \pm 0.5$ & $0.28 \pm 0.04$ & $20 \pm 2$ & $18 \pm 1$ & $2.4 \pm 0.2$ & $236 \pm 11$ \\
\hline & 60 days & $60 \pm 2$ & $14 \pm 1$ & $5.3 \pm 0.5$ & $0.36 \pm 0.04$ & $20 \pm 2$ & $18 \pm 1$ & $2.2 \pm 0.2$ & $227 \pm 15$ \\
\hline & ANOVA $p$-value $(\mathrm{n}=36)^{3}$ & 0.026 & $<0.001$ & 0.219 & $<0.001$ & $<0.001$ & 0.002 & $<0.001$ & $<0.001$ \\
\hline $\mathrm{IF} \times \mathrm{ST}$ & $p$-value $(\mathrm{n}=180)^{4}$ & $<0.001$ & $<0.001$ & $<0.001$ & $<0.001$ & $<0.001$ & $<0.001$ & $<0.001$ & $<0.001$ \\
\hline
\end{tabular}

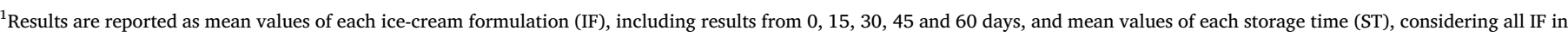
each ST.

${ }^{2}$ If $p<0.05$, the corresponding parameter presented a significantly different value for at least one IF.

${ }^{3}$ If $p<0.05$, the corresponding parameter presented a significantly different value for at least one ST.

${ }^{4}$ In this table, the interaction among factors was significant in all cases; thereby no multiple comparisons could be performed.

Table 2

Colour parameters measured in different ice-cream formulations (IF) and storage times (ST). Results are presented as mean \pm standard deviation. ${ }^{1}$

\begin{tabular}{|c|c|c|c|c|c|c|c|}
\hline & & \multicolumn{3}{|l|}{ Fresh } & \multicolumn{3}{|c|}{ Lyophilized } \\
\hline & & $L^{*}$ & $a^{*}$ & $b^{*}$ & $L^{*}$ & $a^{*}$ & $b^{*}$ \\
\hline \multirow[t]{5}{*}{ IF } & $\mathrm{CI}$ & $94 \pm 1$ & $-2.5 \pm 0.2$ & $13 \pm 1$ & $95 \pm 1$ & $-2.3 \pm 0.2$ & $11 \pm 1$ \\
\hline & BSI & $93 \pm 1$ & $2.0 \pm 0.2$ & $8.1 \pm 0.4$ & $94 \pm 1$ & $1.7 \pm 0.3$ & $8 \pm 1$ \\
\hline & GGI & $86 \pm 3$ & $8 \pm 1$ & $2.4 \pm 0.3$ & $87 \pm 2$ & $8 \pm 1$ & $2.5 \pm 0.3$ \\
\hline & BVI & $85 \pm 2$ & $10 \pm 2$ & $3.0 \pm 0.4$ & $87 \pm 1$ & $10 \pm 1$ & $3.4 \pm 0.4$ \\
\hline & ANOVA $p$-value $(\mathrm{n}=45)^{2}$ & $<0.001$ & $<0.001$ & $<0.001$ & $<0.001$ & $<0.001$ & $<0.001$ \\
\hline \multirow[t]{6}{*}{ ST } & 0 days & $91 \pm 3$ & $4 \pm 4$ & $7 \pm 5$ & $91 \pm 3$ & $4 \pm 4$ & $6 \pm 4$ \\
\hline & 15 days & $90 \pm 4$ & $4 \pm 6$ & $7 \pm 5$ & $90 \pm 5$ & $5 \pm 5$ & $6 \pm 3$ \\
\hline & 30 days & $89 \pm 5$ & $5 \pm 5$ & $7 \pm 4$ & $91 \pm 5$ & $4 \pm 5$ & $6 \pm 3$ \\
\hline & 45 days & $88 \pm 5$ & $4 \pm 5$ & $6 \pm 4$ & $91 \pm 3$ & $4 \pm 5$ & $6 \pm 4$ \\
\hline & 60 days & $89 \pm 5$ & $4 \pm 5$ & $6 \pm 4$ & $90 \pm 4$ & $4 \pm 5$ & $6 \pm 3$ \\
\hline & ANOVA $p$-value $(\mathrm{n}=36)^{3}$ & 0.030 & 0.824 & 0.879 & 0.854 & 0.912 & 0.985 \\
\hline $\mathrm{IF} \times \mathrm{ST}$ & $p$-value $(\mathrm{n}=180)^{4}$ & $<0.001$ & $<0.001$ & $<0.001$ & $<0.001$ & $<0.001$ & $<0.001$ \\
\hline
\end{tabular}

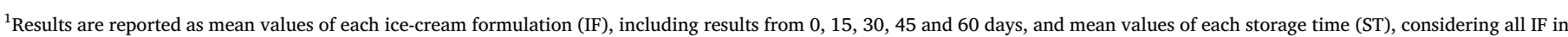
each ST.

${ }^{2}$ If $p<0.05$, the corresponding parameter presented a significantly different value for at least one IF.

${ }^{3}$ If $p<0.05$, the corresponding parameter presented a significantly different value for at least one ST.

${ }^{4}$ In this table, the interaction among factors was significant in all cases; thereby, no multiple comparisons could be performed.

and ST had a significant influence in all evaluated parameters, thereby indicating that the effect of ST over water, fat, protein, ash, carbohydrates (which in this case corresponds to total soluble sugar content) and energy values varied according to each IF. Regarding the effect of each factor per se, it was also significant in most cases, except for protein $(p=0.219)$ along ST and ash $(p=0.243)$ among different IF. Despite not being possible to present the statistical classification, some general tendencies were obtained from the EMM plots. Among different IF, ice-creams incorporating the $B$. vulgaris extract showed the highest contents in water $(63 \pm 1 \mathrm{~g} / 100 \mathrm{~g})$ and protein $(5.8 \pm 0.3 \mathrm{~g} / 100 \mathrm{~g})$ and the lowest levels of carbohydrates $(18 \pm 1 \mathrm{~g} / 100 \mathrm{~g})$, sucrose $(16 \pm 1 \mathrm{~g} / 100 \mathrm{~g})$ and energy $(212 \pm 7 \mathrm{kcal} / 100 \mathrm{~g})$. These results were somehow surprising, since the same batter was used to prepare all icecream formulations, and the incorporation of different colouring additives, owing to the low added quantities, should not interfere with nutritional values. Nevertheless, it might be speculated that ice-cream formulations prepared with $B$. vulgaris were not as stable as the remaining ones, since the presented values correspond to the average values obtained in each storage period. In what regards the effect of ST, 15 days and 45 days stored ice-creams presented the highest fat contents $(15 \pm 1 \mathrm{~g} / 100 \mathrm{~g})$, whilst those stored during 30 days had the lowest energy levels $(210 \pm 11 \mathrm{kcal} / 100 \mathrm{~g})$.

In general, the nutritional profile is in agreement with the reported in typical ice-cream formulation (dos Santos Cruxen et al., 2017), except for protein contents that were detected herein, which were higher than commonly reported values $(2.5-4.5 \mathrm{~g} / 100 \mathrm{~g})$ in ice-cream (Erkaya et al., 2012; Senaka Ranadheera, Evans, Adams, \& Baines, 2013; Silva, Bezerra, Santos, \& Correia, 2015). Protein content is important to the textural properties (emulsification, aeration, water retention, and viscosity) (Cheng, Ma, Li, Yan, \& Cui, 2015), while carbohydrates, mainly sucrose and lactose, are essential to improve taste and retaining aromas (Karaman et al., 2014). 


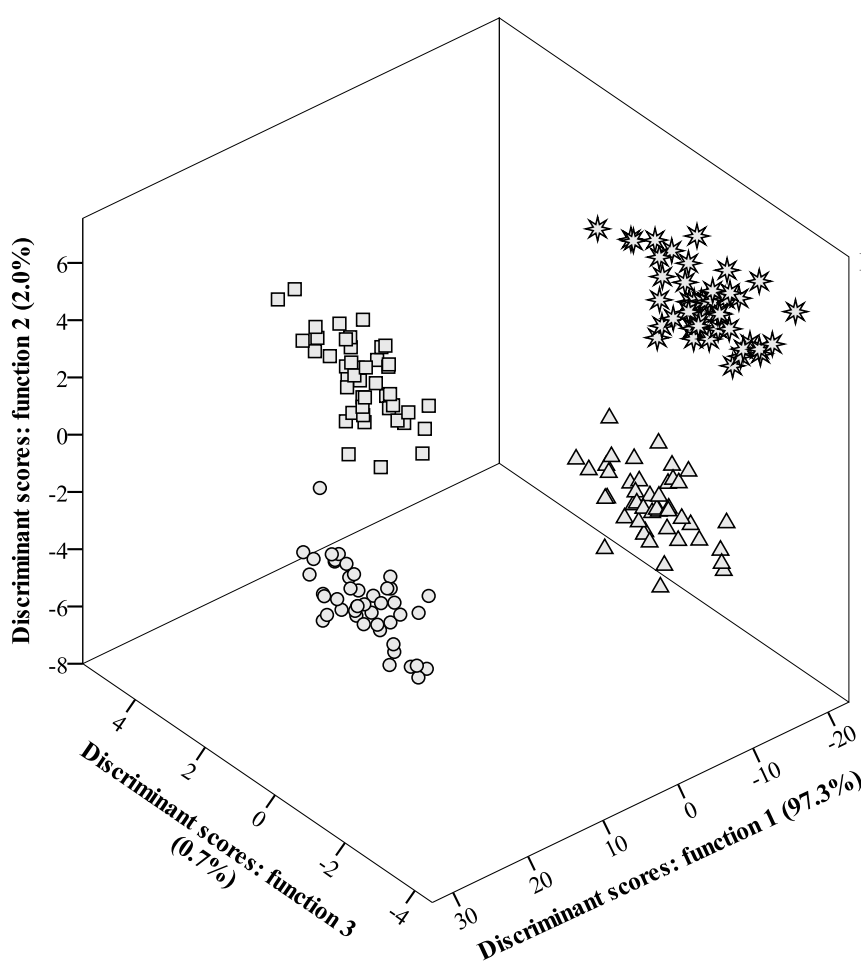

Fig. 1. Spatial distribution of IF markers distributed according to the canonical discriminant functions coefficients defined from results obtained in the laboratorial assays. CI: control ice-cream (O); BSI: ice-cream added with betalain standard ( $\square$ ); GGI: icecream with G. globosa extract ( $($ ) BVI: ice-cream with B. vulgaris extract (流).

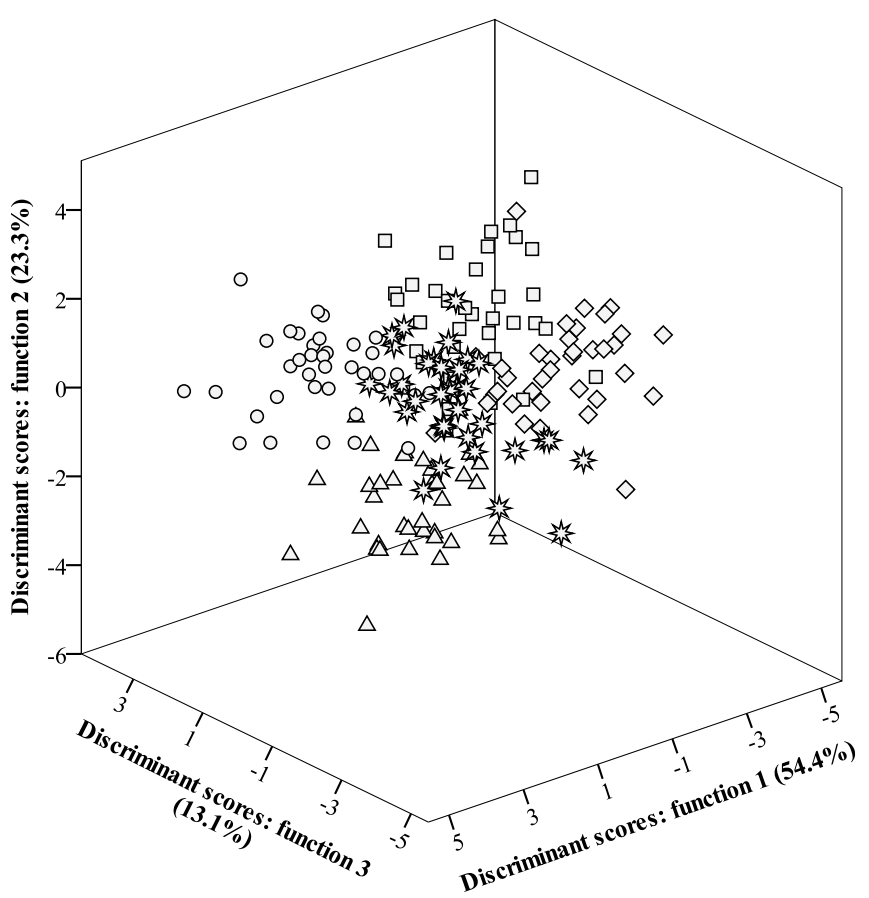

Fig. 2. Spatial distribution of ST markers distributed according to the canonical discriminant functions coefficients defined from results obtained in the laboratorial assays. 0 days: $\bigcirc$; 15 days: $\square$; 30 days: $\triangle$; 45 days: BVI: $\diamond$; 60 days:

Table 2 presents the colour parameters measured for different IF and ST. Considering the main purpose of this work, finding an alternative natural colouring agent for ice-cream, the parameters lightness $\left(L^{*}\right)$, redness $\left(a^{*}\right)$ and blueness $\left(b^{*}\right)$ were evaluated in fresh and lyophilized forms of all IF throughout ST (Table 2). In line with the 
observed in nutritional composition, the studied factors, IF and ST, had a cooperative $(p<0.001)$ effect over colour parameters. However, the effect of ST was not significant in most cases, except $L^{*}$ value in fresh samples ( $p=0.030$ ), while differences among different IF (as it might have been anticipated) were significant in all cases. In general, $L^{*}$ and $b^{*}$ presented the highest values in CI samples, fresh and lyophilized, which on the other hand showed the lowest $a^{*}$ values, owing to the absence of any colouring agent. Concerning IF added with colourants, BSI presented higher $L^{*}$ and $b^{*}$ values, while GGI and BVI were characterized as having the highest $a^{*}$ values. The lower values of $L^{*}$ in GGI and BVI might be explained by the fact that both ingredients are natural extracts, therefore potentially presenting some opacity, as these were not purified compounds.

The major fatty acids of different IF and storage times are shown in Table 3 . The profiles in fatty acids were influenced by ST, especially in the cases of short-chain fatty acids and unsaturated ones. Nevertheless, and despite their statistical significance, the observed differences correspond only to slight variations in the percentages of each fatty acid, which did not seem to be relevant enough to the overall quality of icecreams. This hypothesis is corroborated by the effect of IF, which was only significant in the cases of C14:0, C16:1, C18:1 and MUFA. Likewise, the interaction among factors was not significant for C14:1, C15:0 and C17:0; however, since the individual effect of ST and IF was not significant in these cases, the statistical classification could not be presented. The analysis of the EMM plots of each fatty acid did not allow obtaining overall tendencies, except for the generally higher percentages of C12:0 in ice-creams stored for 45 days, C13:0 in nonstored ice-creams and C16:0 in ice-creams stored during 15 days.

In addition to the tabled fatty acids, C11:0, C13:0, C18:3n3, C20:0, $\mathrm{C} 20: 3 \mathrm{n} 6$ and $\mathrm{C} 20: 4 \mathrm{n} 6$ were also detected, but in percentages lower than $0.5 \%$. Nevertheless, all quantified fatty acids were included in the linear discriminant analyses discussed in the next section.

Furthermore, the extracts, the commercial standard and the icecream samples did not show hepatotoxicity up to the maximal assayed concentration $(400 \mu \mathrm{g} / \mathrm{mL})$ as indicated by the results obtained with the PLP2 cell line (isolated from porcine liver). The quantities of betacyanins were also maintained along ST, as it was validated according to the chromatographic results from HPLC-DAD-ESI/MS, showing their suitability as potentially useful stable colouring agents.

\subsection{Linear discriminant analysis}

After comparing the evaluated parameters one by one, weighing the significance of changes caused by either IF or ST, a linear discriminant analysis was applied to find the parameters suffering the highest changes in each IF or ST. This was specifically achieved by assessing the linkage between IF or ST (categorical dependent variables) and the matrix of obtained results (quantitative independent variables).

Fig. 1 presents the spatial distribution of IF markers distributed according to the canonical discriminant functions coefficients defined from results obtained in the laboratorial assays. In what concerns the IF effect, the three defined discriminant functions included $100.0 \%$ (first function: $97.3 \%$; second function: $2.0 \%$; third function: $0.7 \%$ ) of the observed variance (Fig. 1). From the 36 analysed variables, the model selected 17: water, protein, sucrose, energy, $L^{*}$ (fresh and lyophilized), $a^{*}$ (fresh and lyophilized), $b *$ (fresh and lyophilized), C6:0, C10:0, C11:0, C13:0, C16:1, C18:1 and C20:4 as those having discriminant effect. As it might be concluded, function 1 included a considerably high percentage of variance, thereby indicating that the variables more correlated with this function (specifically $b^{*}$ in lyophilized samples, $b^{*}$ in fresh samples and $a^{*}$ in fresh samples) were the ones presenting the highest changes within different IF. Accordingly, function 1 separated mostly one group (high $b^{*}$ values) formed by CI and BSI from a second group (high $a^{*}$ values) formed by GGI and BVI. Function 2, on the other hand, was more highly correlated to water, sucrose and protein contents, being effective in separating markers corresponding to BVI. Finally, function 3, despite the low percentage of explained variance, was useful to separate CI from BSI, mostly due to their differences in $L^{*}$ (fresh and lyophilized), $a^{*}$ (lyophilized) and energy values. The classification performance was $100 \%$ accurate, either for original grouped cases, as well as for the cross-validated grouped cases.

The spatial distribution of ST markers scattered according to the canonical discriminant functions coefficients defined from results obtained in the laboratorial assays is presented in Fig. 2. A completely different outcome was obtained when comparing the effect ST of all parameters simultaneously. In fact, the differences observed in each ST $(0,15,30,45$ and 60 days) were not enough to discriminate their corresponding markers (Fig. 2). Actually, several results were misclassified (i.e., results from a determined storage time were classified as belonging to a different period) by the leave-one-out validation procedure, proving that ST, up to the assayed periods, did not act as a significant source of variability for nutritional and colour parameters, probably due to the low storage temperature $\left(-22^{\circ} \mathrm{C}\right)$.

\section{Conclusion}

Overall, the extracts obtained from G. globosa might be a suitable alternative as natural colouring agents for ice-cream, as the obtained results in GGI and BVI were quite similar. Comparing both studied factors, ST and IF had significant effects in most nutritional parameters, while colour parameters were not affected by ST (except for $L^{*}$ in lyophilized samples), contrarily to fatty acids, which were mainly altered by ST, showing only minor changes among different IF. Nevertheless, and as evidenced by LDA outputs, the effects of IF were more pronounced than those induced by ST, since markers were only clustered according to the levels of each factor in the case of IF.

\section{Acknowledgments}

The authors are grateful to the Foundation for Science and Technology (FCT, Portugal) and FEDER under Programme PT2020 for financial support to CIMO (UID/AGR/00690/2013); L. Barros and J.C.M. Barreira contracts and C.L. Roriz grant (SFRH/BD/117995/ 2016). This work was also funded by the European Structural and Investment Funds (FEEI) through the Regional Operational Program North 2020, within the scope of Project NORTE-01-0145-FEDER023289: DeCodE and Project Mobilizador ValorNatural'.

\section{References}

Abreu, R. M. V., Ferreira, I. C. F. R., Calhelha, R. C., Lima, R. T., Vasconcelos, M. H., Adega, F., et al. (2011). Anti-hepatocellular carcinoma activity using human HepG2 cells and hepatotoxicity of 6-substituted methyl 3-aminothieno[3,2-b]pyridine-2carboxylate derivatives: In vitro evaluation, cell cycle analysis and QSAR studies. European Journal of Medicinal Chemistry, 46(12), 5800-5806. http://doi.org/10. 1016/j.ejmech.2011.09.029.

AOAC (2016). AOAC Official Methods of Analysis (20th ed.). AOAC International.

Barros, L., Pereira, E., Calhelha, R. C., Dueñas, M., Carvalho, A. M., Santos-Buelga, C., et al. (2013). Bioactivity and chemical characterization in hydrophilic and lipophilic compounds of Chenopodium ambrosioides L. Journal of Functional Foods, 5(4), 1732-1740. http://doi.org/10.1016/j.jff.2013.07.019.

Bridle, P., \& Timberlake, C. F. (1997). Anthocyanins as natural food colours-selected aspects. 58(1).

Carocho, M., Barreiro, M. F., Morales, P., \& Ferreira, I. C. F. R. (2014). Adding molecules to food, pros and cons: A review on synthetic and natural food additives. Comprehensive Reviews in Food Science and Food Safety. http://doi.org/10.1111/1541 4337.12065.

Carocho, M., Morales, P., \& Ferreira, I. C. F. R. (2015). Natural food additives: Quo vadis? Trends in Food Science \& Technology, 45(2), 284-295. http://doi.org/10.1016/j.tifs. 2015.06.007.

Chaikham, P., \& Rattanasena, P. (2017). Combined effects of low-fat ice cream supplemented with probiotics on colon microfloral communities and their metabolites during fermentation in a human gut reactor. Food Bioscience, 17, 35-41. http://doi. org/10.1016/j.fbio.2016.12.005.

Cheng, J., Ma, Y., Li, X., Yan, T., \& Cui, J. (2015). Effects of milk protein-polysaccharide interactions on the stability ofice cream mix model systems. Food Hydrocolloids, 45, 327-336. http://doi.org/10.1016/j.foodhyd.2014.11.027.

Edmonds, L., Wadhwa, S. S., \& Wibisono, R. (2013). Producing ice cream using a 
substantial amount of juice from kiwifruit with green, gold or red fl esh. FRIN, 50(2), 647-656. http://doi.org/10.1016/j.foodres.2011.05.030.

Erkaya, T., Dağdemir, E., \& Sengül, M. (2012). Influence of Cape gooseberry (Physalis peruviana L.) addition on the chemical and sensory characteristics and mineral concentrations of ice cream. Food Research International, 45(1), 331-335. http://doi. org/10.1016/j.foodres.2011.09.013.

Fernandes, Â., Antonio, A. L., Barreira, J. C. M., Oliveira, M. B. P. P., Martins, A., \& Ferreira, I. C. F. R. (2012). Effects of gamma irradiation on physical parameters of Lactarius deliciosus wild edible mushrooms. Postharvest Biology and Technology, 74, 79-84. http://doi.org/10.1016/j.postharvbio.2012.06.019.

González, M., Gallego, M., \& Valcárcel, M. (2002). Automatic screening method for the rapid and simple discrimination between synthetic and natural colorants in foods. Analytica Chimica Acta, 464, 237-247.

Karaman, S., Toker, Ö. S., Yüksel, F., Çam, M., Kayacier, A., \& Dogan, M. (2014). Physicochemical, bioactive, and sensory properties of persimmon-based ice cream: Technique for order preference by similarity to ideal solution to determine optimum concentration. Journal of Dairy Science, 97(1), 97-110. http://doi.org/10.3168/jds. 2013-7111.

Machewad, G., Chatge, P., Chappalwar, V., Jadhav, B., \& Chappalwar, A. (2012). Studies on extraction of safflower pigments and its utilization in ice cream. Journal of Food Processing \& Technology, 3, 172-174.

Martin, F., Oberson, J. M., Meschiari, M., \& Munari, C. (2016). Determination of 18 water-soluble artificial dyes by LC-MS in selected matrices. Food Chemistry, 197, 1249-1255. http://doi.org/10.1016/j.foodchem.2015.11.067.

Moriano, M. E., \& Alamprese, C. (2017). Honey, trehalose and erythritol as sucrose-alternative sweeteners for artisanal ice cream. A pilot study. LWT - Food Science and Technology, 75, 329-334. http://doi.org/10.1016/j.lwt.2016.08.057.

Roriz, C. L., Barros, L., Carvalho, A. M., \& Ferreira, I. C. F. R. (2014). HPLC-profiles of tocopherols, sugars, and organic acids in three medicinal plants consumed as infusions. International Journal of Food Science, 2014(5)http://doi.org/10.1155/2014/ 241481.

Roriz, C. L., Barros, L., Carvalho, A. M., Santos-Buelga, C., \& Ferreira, I. C. F. R. F. R. (2014). Pterospartum tridentatum, Gomphrena globosa and cymbopogon citratus: A phytochemical study focused on antioxidant compounds. Food Research International, 62, 684-693. http://doi.org/10.1016/j.foodres.2014.04.036.

Roriz, C. L., Barros, L., Prieto, M. A., Barreiro, M. F., Morales, P., \& Ferreira, I. C. F. R. (2017). Modern extraction techniques optimized to extract betacyanins from
Gomphrena globosa L. Industrial Crops and Products, 105(May), 29-40. http://doi. org/10.1016/j.indcrop.2017.05.008.

Roriz, C. L., Barros, L., Prieto, M. A., Morales, P., \& Ferreira, I. C. F. R. (2017). Floral parts of Gomphrena globosa L. as a novel alternative source of betacyanins: Optimization of the extraction using response surface methodology, Vol. 229, 223-234. http://doi.org/10. 1016/j.foodchem.2017.02.073.

Sanguigni, V., Manco, M., Sorge, R., Gnessi, L., \& Francomano, D. (2016). Natural antioxidant ice cream acutely reduces oxidative stress and improves vascular function and physical performance in healthy individuals. Nutrition (Burbank, Los Angeles County, Calif.), 33, 1-9. http://doi.org/10.1016/j.nut.2016.07.008.

dos Santos Cruxen, C. E., Hoffmann, J. F., Zandoná, G. P., Fiorentini, Â. M., Rombaldi, C. V., \& Chaves, F. C. (2017). Probiotic butiá (Butia odorata) ice cream: Development, characterization, stability of bioactive compounds, and viability of Bifidobacterium lactis during storage. LWT - Food Science and Technology, 75, 379-385. http://doi. org/10.1016/j.lwt.2016.09.011.

Senaka Ranadheera, C., Evans, C. A., Adams, M. C., \& Baines, S. K. (2013). Production of probiotic ice cream from goat's milk and effect of packaging materials on product quality. Small Ruminant Research, 112(1-3), 174-180. http://doi.org/10.1016/j. smallrumres.2012.12.020.

Silva, P. D. L. da, Bezerra, M. de F., Santos, K. M. O. dos, \& Correia, R. T. P. (2015). Potentially probiotic ice cream from goat's milk: Characterization and cell viability during processing, storage and simulated gastrointestinal conditions. LWT - Food Science and Technology, 62(1), 452-457. http://doi.org/10.1016/j.lwt.2014.02.055.

Soukoulis, C., Lyroni, E., \& Tzia, C. (2010). Sensory pro fi ling and hedonic judgement of probiotic ice cream as a function of hydrocolloids, yogurt and milk fat content. LWT Food Science and Technology, 43(9), 1351-1358. http://doi.org/10.1016/j.lwt.2010. 05.006.

Soukoulis, C., \& Tzia, C. (2018). Grape, raisin and sugarcane molasses as potential partial sucrose substitutes in chocolate ice cream: A feasibility study. International Dairy Journal, 76, 18-29. https://doi.org/10.1016/j.idairyj.2017.08.004.

Spórna-kucab, A., \& Jagodzi, J. (2017). Separation of betacyanins from purple flowers of Gomphrena globosa, Vol. 1489, 51-57. http://doi.org/10.1016/j.chroma.2017.01. 064.

Wissgott, U., \& Bortlik, K. I. (1996). Prospects for new natural food colorants. Trends in Food Science \& Technology, 7(9), 298-302. http://doi.org/10.1016/0924-2244(96) 20007-X. 